\title{
An Overview of Electrokinetic Remediation Assisted Phytoremediation to Remediate Barren Acidic Soil
}

\author{
Jamil N. ${ }^{1, a}{ }^{*}$, Madun A. ${ }^{2, b}$, Ahmad Tajudin S. $A^{3, c}$ and Embong $Z^{4, d}$ \\ ${ }^{1,2,3}$ Faculty of Civil and Environmental engineering \\ ${ }^{4}$ Faculty of Science, Technology and Human Development \\ Universiti Tun Hussien Onn Malaysia \\ 86400 Parit Raja, Batu Pahat Johor \\ a shafieera90@gmail.com, baziman@uthm.edu.my, csaifulaz@uthm.edu.my, ${ }^{\mathrm{d}}$ zaidi@uthm.edu.my
}

Keywords: electrokinetic remediation, phytoremediation, barren acidic soil, ion migration,

\begin{abstract}
Electrokinetic has proven to be alternative technique to remediate pollution and increase soil strength for soft soil. This remediation method has been applied to remediate the hydrocarbon and heavy metal contaminant. Phytoremediation is a technique used to remediate the hydrocarbon and heavy metal contaminant. Both of this remediation technique has been proven as attractive alternative to clean up polluted soils. Although barren acidic soil is not categories as hazardous, the necessity of covered soil surface is on demand in order to minimize the surface erosion. Other than that, this remediation technology also helps in horticulture in order to enlarge the plantation and farming area. This paper will explain the formation of barren acidic soil, principles electrokinetic remediation for remediation of barren acidic soil and application of phytoremediation in order to sustain the process of remediation. Correlation of both remediation methods will minimize the acidic ion migration and sustain the $\mathrm{pH}$ value on soil surface for grass, vegetable or palm oil plantation.
\end{abstract}

\section{Introduction}

Modernization via construction give bad impact to the environment especially to the concept of sustainability when the developer ignoring it. According to Gordon [1], the major cause for soils to become acid are rainfall and leaching, acidic parent material, organic matter decay and also harvest of high yielding crops. Soil acidifications have major impact to the landscape environment since acidification of soil can infertile the soil, which causing the surface becomes barren and unfavourable [2]. The process of soil acidification takes place when the subsoil or parent material containing acidic ion was exposed to the atmosphere. The problem faced by barren acidic soil is surface erosion. These problems are not only occurring on flat area but also in slope area. According to Zachar [3], in extreme cases, the bedrock exposed to the atmosphere where it should be covered by sparse or low vegetation. The destruction of this type of land is a consequence of overgrazing and increase the acceleration of erosion. Term "barrens" is used to describe regions that have poor nutrient to support vegetative species that are adapted to their ecology [4]. The term "barrens" expressed a term for poor farmland, or that it lacks aesthetic landscape while the ecologist describe barren soil as edaphic drought and soil infertile [5]. To minimize this problem, remediation of barren soil needs to be done. This paper will discuss the remediation process using electrokinetic and phytoremediation. Both remediation techniques are a laboratory scale with control environment.

\section{Barren Acidic Soil}

All barren lands are notable for their critical ecological environment with insufficient protection against destructive agents as shown in Fig. 1. Vereda-Alonso et al. [5] stated that barren land shows a shallow soil profile, the nature of the bedrock is of considerable importance of their classification and identification. Barren acidic soils are shallow, sandy and acidic [6,7]. From the study 
conducted by Faizun [8], Malaysian barren acidic soils located at Ayer Hitam, Johor characterise differ with Cranfill [7] and Homoya [6]. Faizun [8] stated that the soil is clay and silt with a depth of 5 to $10 \mathrm{~m}$ from the surface and extremely acidic with a $\mathrm{pH}$ value of 2.36 to 2.80 . Overall, definitions of barren soil are mostly similar among the researchers as presented in Table 1.

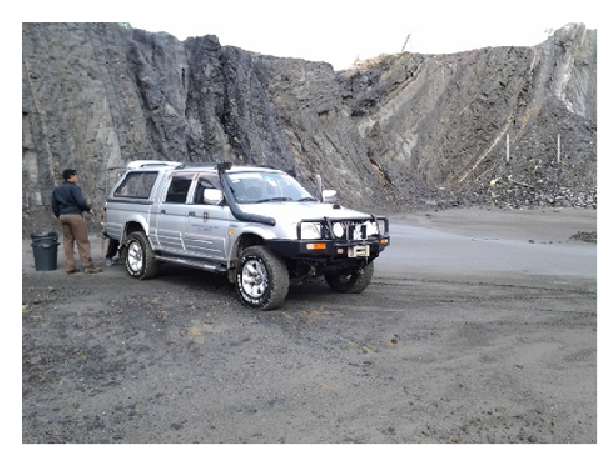

Fig. 1 Location of barren acidic soil at Ayer Hitam, Johor (After Faizun [8])

Tufail et al. [9] mentioned that the electrical conductivity of barren soil decreases with depth compared to cultivated soils found in Faisalabad, Pakistan. Barren soil containing higher salt hazard (saline soil) compared to cultivated soil. This behaviour indicates that the mineral accumulated at the upper surface of barren soil and the mineral is keep mixings at the cultivated soil. Other than that, the $\mathrm{pH}$ value of barren soil and cultivated is increasing with depth where the cultivated soil is less acidic.

Table 1: Definition of barren soils (After Homoya [6])

\begin{tabular}{|c|c|}
\hline Author & Description \\
\hline Morse (1983) & steep, south-facing slope, treeless openings of shale-flake talus \\
\hline Wherry 1963 & $\begin{array}{l}\text { land underlain by sand or gravel, from the upper levels of which mineral } \\
\text { constituents other than silica have been leached, deficiency of mineral } \\
\text { nutrients, markedly dry }\end{array}$ \\
\hline DeSelm 1990 & acid, infertile, and droughty \\
\hline Cranfill 1991 & soils are shallow, sandy and acidic \\
\hline Keith 1981 & severe soil moisture depletion \\
\hline $\begin{array}{l}\text { Winterringer and } \\
\text { Vestal } 1956\end{array}$ & unfavorable to plant growth \\
\hline Forman 1979 & $\begin{array}{l}\text { sandy or shallow soil with frequent fire, high acidity and scarce nutrients, } \\
\text { and abundant heaths and crooked pines }\end{array}$ \\
\hline $\begin{array}{l}\text { Frost and } \\
\text { Musselman } 1987\end{array}$ & open canopy, small stature of vegetation, and exposed patches of sand \\
\hline Keener 1983 & high insolation temperatures and low moisture conditions at the surface \\
\hline Strang 1972 & $\begin{array}{l}\text { rocky heathlands...closely correlated with topographic position and depth of } \\
\text { soil over the impenetrable pan }\end{array}$ \\
\hline
\end{tabular}

\section{Formation}

Many barren soils are contained pyrite mineral [4]. According to Brandy and Weil [10] formation of barren acidic soil is based on the oxidation of sulphur element found in the soil. Product of oxidation sulphur is sulphuric acid. These oxidation processes normally occur with the presence of pyrite element. Chemical reaction of oxidation of pyrite minerals: 
$\mathrm{FeS}_{2}+31 / 2 \mathrm{O}_{2}+\mathrm{H}_{2} \mathrm{O}=\mathrm{FeSO}_{4}+2 \mathrm{H}^{+}+\mathrm{SO}_{4}{ }^{2-}$

From the equation $\mathrm{FeS}_{2}$ is the empirical formula for pyrite. Presence of excess oxygen and water produce a product of $\mathrm{FeSO}_{4}$ which is ferrous sulphate and $2 \mathrm{H}^{+}+\mathrm{SO}_{4}{ }^{2-}$ which stand for dissociated sulphuric acid. This dissociated sulfuric acid is then exposed to the water catchment area will influence the water become acidic. These related reactions are responsible for producing large amount of acidity and reduce the presence of sulphur in the soil. Oxygen level increase by drainage or excavation of the soil surface.

$$
\mathrm{H}_{2} \mathrm{SO}_{4}=2 \mathrm{H}^{+}+\mathrm{SO}_{4}{ }^{2-}
$$

From equation (1) and (2), formation of hydrogen ion has increased the availability to react with other acid functional group which then can be dissociated. From x-ray flurosence data observed by Faizun [8] the percentage of aluminium oxide, $\mathrm{Al}_{2} \mathrm{O}_{3}$ is $26.90 \%$ contributes to cations acid.

\section{Electrokinetic Remediation}

Electrokinetic is a process of treatment of soil without disturbing the soil through excavation or deep-mixing. Electrokinetic remediation is conducted by inserting two electrodes known as anode and cathode into the soil through the drilling and application of direct current to mobilise ion between these two electrodes at the specified treatment area. Three parameters that control the electrokinetic process are type of electrode, type of electrolyte and direct current (DC) voltage with duration of current applied. Electrokinetic method can be applied into two different applications i.e., geoenvironmental and ground treatment. Electrokinetic remediation is more on contamination soil application while electrokinetic stabilisation is more related to ground improvement application.

\section{Electrokinetic Remediation Setup}

Fig. 2 shows the electrokinetic set up at laboratory scale to investigate the ions movement through soil During electrokinetic remediation, electrode provides and electric field across the soft soil. Electrode promotes migration of electrolyte in the soil media.

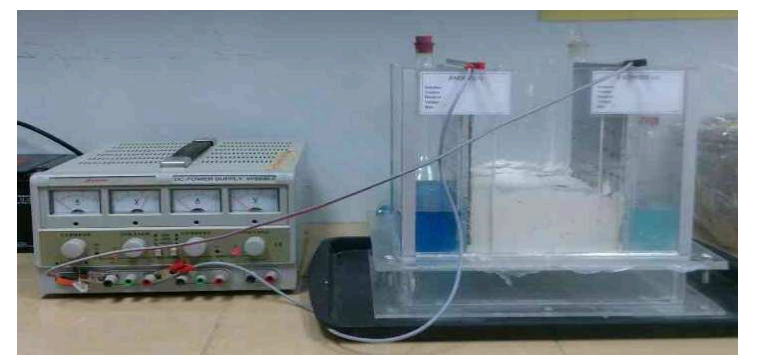

Fig. 2 Electrokinetic remediation setup at laboratory scale (After Jamil [11]).

Electrodes establish the point where the current change from an 'electronic character' to the 'ionic'. Electrodes electrons exchanged between the metallic phase and electrolyte in solution. In order for this to occur, reactions will base on Faraday's law which formulated as "When 96485 Coulombs pass through solution, at both the electrodes a gram equivalent of 45 substances is released". Corrosion in electrochemical process is nature. It involves the unprompted oxidation reaction in the presence of an aqueous environment. This process is also known as metal-dissolution reaction and the product of being ionic species: authorities where the work was carried out.

$$
\mathrm{Me} \rightarrow \mathrm{Me}^{\mathrm{n}+}+\mathrm{ne}^{-}
$$


Where Me refer to metal used as electrodes, $\mathrm{Me}^{\mathrm{n}+}$ is ions of the metal and $\mathrm{n}$ is the number of electrons $\left(\mathrm{e}^{-}\right)$. This metal ion then acts as a cementing agent when it precipitates during interparticle contact and increase media strength.

The electrolyte is a solution placed at the anode and cathode that used to extract contaminant as the contaminant changes in ionic form. Researcher used anode as chemical liquid and cathode as distilled water. Electrolyte conditioning enhanced removal of contaminant and decreased energy consumption from enhancement in dissolution of soil mineral and supply of ions [12]. Electrolyte conditioning with strongly acidic or basic solution decreased dramatically with energy consumption, which is a critical factor. Nowadays, different solutions are being studied to enhance the transport and extraction of contaminants and to prevent the formation of precipitates [5]. The present of electrolyte increase the applied voltage up to $70 \%$ compared to about $30 \%$ without electrolyte [13]. This result shows that the electrolyte function as a medium of the electric field pass through and ion mobilization (electromigration) can take place.

Ahmad Tajudin [13] used constant voltage of $50 \mathrm{~V} / \mathrm{m}$ for 3, 7 and 14 days period of time. These voltage gradients control the magnitude of voltage throughout the experiment. Mitchell and Soga [14] had proposed the voltage gradient for geotechnical purposes is between 40 and $60 \mathrm{~V} / \mathrm{m}$.

\section{Phytoremediation}

Phytoremediation is using plant to absorb the heavy metals, hydrocarbon contaminant and mineral in soil or slurry thus reducing the risk for environmental degradation from leaching to groundwater [15]. This technique is successfully applied abroad, for example, it has been applied to remediate radioactivity pollution in Japan in the year 2011.

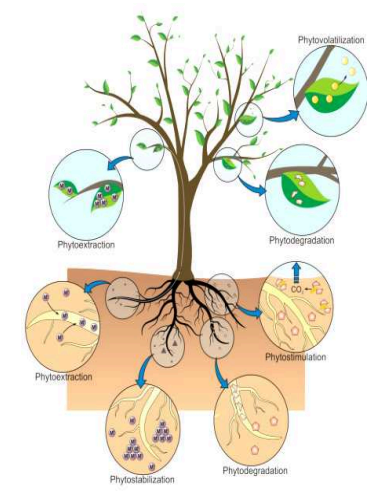

Fig. 3 Phytoremediation concept in contaminant elimination (After Cristofaki [15])

Phytoremediation technique for barren acidic soil using Dieffenbachia as native plant shows that there are increasing in $\mathrm{pH}$ value from 2.36 to 4.30 on sample from Ayer Hitam, Johor [8]. Therefore, it has been proven that this technique is suitable to be applied on barren acid soil in Malaysia. According to Collin [17] phytoremediation also act as surface cover. This remediation process was applied to hydrocarbon contaminant. Collin [16] applied phytoremediation technique using grasses since they have fibrous roots that can penetrate into a large soil volume and can provide a good surface cover to suppress dust. Fig. 3 shows that the plants root is used to eliminate contaminant in soils.

\section{Summary}

Remediation of natural contamination using both remedial techniques can be applied on barren soil. The electrokinetic remediation is used to increase the soil $\mathrm{pH}$ and supply the nutrient into the soil whereas the phytoremediation technique can be performed after electrokinetic remediation for 
continuous remediation process (long term effects). In addition, phytoremediation also act as soil surface protection which decrease the velocity of surface water run-off during heavy rainfall.

\section{Acknowledgement}

The authors would like to thank the Ministry of Higher Education and Universiti Tun Hussein Onn, Malaysia for supporting this research under Exploratory Research Grant Scheme (ERGS) Vot. E040.

\section{References}

[1] V. J Gordon: Cause and Effect of Soil Acidity.(2012) Publication Oklahoma State University.

[2] Salt D.E. et al,. Phytoremediation: A Novel Strategy for the Removal of Toxic Metals from the Environment using Plants Bio/Tech. (1995) p. 468-474.

[3] D. Zachar: Forest Amelioration. Developments in Agricultural and Managed Forest Ecology Vol. 14, (1984) p. 454-480.

[4] M. A. Edwards, M. Winslow \& R. Blake: Assessing Pine Barrens Soil Moisture Regimes Using Synthetic Aperture Radar (SAR) Techniques. IEEE International Geoscience and Remote Sensing Symposium, (2007) p. 1828-1831.

[5] C. Vereda-Alonso, C. Heras-Lois, C. Gomez-Lahoz, F. Garcia-Herruzo \& J. M. RodriguezMaroto: Ammonia enhanced two-dimensional electrokinetic remediation of copper spiked kaolin. Electrochimica Acta, 52(10), (2007) p. 3366-3371.

[6] M. A. Homoya: Barren as Ecological Term: An Overview of Usage in the Scientific Literature. North American Conference on Savannasand Barrens, (1994).

[7] R. Cranfill: Flora of Hardin County, Kentucky. Castanea 56 (1991) p. 228-267.

[8] A. H. Faizun: Phytoremediation Technique to Remediate the Acidic Soil Sampled at Ayer Hitam, Johor (2014). Universiti Tun Hussien Onn Malaysia.

[9] M. Tufail, N. Akhtar \& M. Waqas: Measurement of terrestrial radiation for assessment of gamma dose from cultivated and barren saline soils of Faisalabad in Pakistan. Radiation Measurements, 41(4), (2006) p. 443-451.

[10] N. C. Brady and R.R. Weil: The Nature and Properties of Soils Pearson. Practice Hall. (2008).

[11] N. Jamil: Electrokinetic Remediation of Acidic Soft Soil. (2014) Universiti Tun Hussien Onn Malaysia.

[12] K. Baek, D.H. KimPark, S.-W., B.-G. Ryu, T. Bajargal, \& J. -S. Yang: Electrolyte conditioning-enhanced electrokinetic remediation of arsenic-contaminated mine tailing. Journal of Hazardous Materials, 161(1), (2009) p. 457-62.

[13] S. A. A. Tajudin: Electrokinetic Stabilisation of Soft Clay. (2012) University of Birmingham.

[14] J.K. Mitchell \& K. Soga: Fundamentals of Soil Behaviour. 3rd Edition, John Wiley \& Sons, New York. (2005).

[15] D.E. Salt et. al.: Phytoremediation: A Novel Strategy for the Removal of Toxic Metals from the Environment using Plants Bio/Tech. (1995) p. 468-474.

[16] M. I. Cristofaki: Effect of Heavy Metal Stress in Plant Metabolism of Solanaceous Plant Species with Emphasis on Nitrogen Assimilation. (2011) Cranfield University.

[17] C. D. Collin: Implementing Phytoremediation of Petroleum Hydrocarbons, Method in Biotechnology, vol 23: Methods and Reviews (2). 